OPEN ACCESS

Edited by:

Peng Qu,

National Institutes of Health $(\mathrm{NIH})$,

United States

Reviewed by:

Hanming Jiang,

Shandong First Medical University,

China

Guohao Wang,

National Institutes of Health $(\mathrm{N} / \mathrm{H})$,

United States

*Correspondence:

Zhi-Dong Qiu

qzd_ccucm@163.com

Da Liu

liuda_1986@163.com

Specialty section:

This article was submitted to Pharmacology of Anti-Cancer Drugs,

a section of the journal

Frontiers in Oncology

Received: 29 November 2020 Accepted: 31 December 2020 Published: 18 February 2021

Citation:

Liu T-J, Hu S, Qiu Z-D and Liu D (2021) Anti-Tumor Mechanisms Associated With

Regulation of Non-Coding RNA by Active Ingredients of Chinese Medicine: A Review.

Front. Oncol. 10:634936. doi: 10.3389/fonc.2020.634936

\section{Anti-Tumor Mechanisms Associated With Regulation of Non-Coding RNA by Active Ingredients of Chinese Medicine: A Review}

\author{
Tian-Jia Liu, Shuang Hu, Zhi-Dong Qiu ${ }^{*}$ and Da Liu * \\ School of Pharmacy, Changchun University of Chinese Medicine, Changchun, China
}

Cancer has become the second leading cause of death worldwide; however, its complex pathogenesis remains largely unclear. Previous research has shown that cancer development and progression are closely associated with various non-coding RNAs, including long non-coding RNAs and microRNAs, which regulate gene expression. Target gene abnormalities are regulated and engaged in the complex mechanism underlying tumor formation, thereby controlling apoptosis, invasion, and migration of tumor cells and providing potentially effective targets for the treatment of malignant tumors. Chemotherapy is a commonly used therapeutic strategy for cancer; however, its effectiveness is limited by general toxicity and tumor cell drug resistance. Therefore, increasing attention has been paid to developing new cancer treatment modalities using traditional Chinese medicines, which exert regulatory effects on multiple components, targets, and pathways. Several active ingredients in Chinese medicine, including ginsenoside, baicalin, and matrine have been found to regulate ncRNA expression levels, thus, exerting anti-tumor effects. This review summarizes the scientific progress made regarding the anti-tumor mechanisms elicited by various active ingredients of Chinese medicine in regulating non-coding RNAs, to provide a theoretical foundation for treating tumors using traditional Chinese medicine.

Keywords: microRNA, IncRNA, non-coding RNA, active ingredients of Chinese medicine, anti-cancer

\section{INTRODUCTION}

The incidence of cancer has tripled over the past three decades and is expected to increase five-fold by 2030 (1). Nevertheless, the precise mechanism associated with cancer pathogenesis remains largely unclear as it is highly complex and diverse. Since the 1970s, gene therapy has become an increasingly attractive strategy for the treatment of various diseases. Accordingly, more recently, the focus has shifted toward identifying specific genetic etiologies of cancer to design effective gene

Abbreviations: ncRNA, non-coding RNA; lncRNA, long non-coding RNA; miRNA, microRNA; siRNA, small interfering RNA; piRNA, Piwi-interacting RNA; rRNA, ribosomal RNA; tRNA, transfer RNA; snRNA, small nuclear RNA; EMT, epithelial-mesenchymal transition; ceRNA, competing endogenous RNA; T-ALL, T-cell acute lymphoblastic leukemia; B-ALL, B-cell acute lymphoblastic leukemia; PKM2, pyruvate kinase M2; MMPs, Matrix metalloproteinases; circRNA, circular RNA. 
therapies to overcome the challenges associated with traditional cancer treatment modalities. As the human genome is gradually deciphered, RNA has been shown to play an auxiliary role as an intermediate vector of genetic information, and an increasing number of regulatory functions have been ascribed to this class of molecules. In particular, non-coding sequences, which account for $99 \%$ of the total human genome, have received greater attention (2). Most of the identified non-coding RNAs (ncRNAs), including long non-coding (lnc)RNAs, micro (mi) RNAs, small interfering (si)RNAs, Piwi-interacting (pi)RNAs, ribosomal (r)RNAs, transfer (t)RNAs, and small nuclear ( $\mathrm{sn}$ ) RNAs, participate in the translation, modification, and other cellular functions. Among these molecules, lncRNAs and miRNAs have been researched more intensively to decipher their fundamental roles in many diseases, including cancer (3). In fact, IncRNAs were initially believed to be the "noise" of genome transcription, a by-product of RNA polymerase II transcription, and were considered biologically non-functional (4). However, recent studies have shown that lncRNAs play an essential role in cancer signal transduction pathways by interacting with proteins and RNA (5) and are reportedly associated with various cancers, including those of the stomach (6-8), lung $(9,10)$, breast $(11,12)$, and prostate $(13,14)$. Specifically, inhibition of lncRNA H19 and lncRNA PVT1 expression can effectively inhibit the cancerization, metastasis (15), and angiogenesis (7) of gastric cancer.

miRNA is a class of small (18-22 nucleotides) ncRNA molecules; it is present in all eukaryotic cells, with over 2,000 of these RNAs being identified in humans (3). However, ncRNAs have also been described in insects, plants, fungi, bacteria, and viruses $(16,17)$. Compared with $\operatorname{lncRNA}$, the regulatory mechanism of miRNA is relatively simple and clear. It regulates gene expression by either suppressing mRNA translation or degrading mRNA molecules (18). Previous studies have found that the abnormal expression of miRNAs can disrupt many signaling pathways resulting in reduced proliferation, migration, and invasion of cancer cells and the promotion of apoptosis (19-21). Numerous carcinogenic miRNAs, including miR-638, miR-155, miR-31, miR-21, miR221, miR-222, and miR-294 among others, are overexpressed in various malignant tumors (22-24), whereas others, including miR-429, miR-211, miR-1271, and miR-34a, exert anti-cancer effects and are under-expressed in cancer cells $(25,26)$.

The emergence of ncRNA provides new alternatives for cancer treatment, but its effective application in clinical cancer treatment remains challenging. At present, chemotherapy is one of the most important means of treating malignant tumors. However, its efficacy is limited by systemic toxicity and tumor cell resistance (27). Traditional Chinese medicine has been practiced for thousands of years because of its safety and minimal side effects. To date, many cancer patients have used traditional Chinese medicine as an alternative therapy for cancer treatment (28). Moreover, some of the active ingredients of Chinese medicine have been shown to exert anti-cancer effects by regulating ncRNAs and acting on various signaling pathways and cancer-related molecular targets, thus, inhibiting tumor proliferation, metastasis, and invasion and inducing cancer cell apoptosis (29). For instance, the isoflavone calycosin inhibits nasopharyngeal carcinoma cell growth by regulating the lncRNA EWSAT1 and its downstream TRAF6 pathways (30). Additionally, curcumin upregulates miR-145 expression to inhibit cell proliferation and invasion in vitro, while inducing cell cycle arrest (31). These reports suggested that ncRNA have anti-tumor abilities that regulate cancer cell apoptosis, proliferation, resistance, metastasis, and invasion.

\section{ACTIVE INGREDIENTS OF TRADITIONAL CHINESE MEDICINE REGULATE THE ANTI-TUMOR MECHANISM OF MIRNA}

Over the past decades, miRNA has been shown to play a regulatory role in many cancer signaling pathways (32). The active ingredients in traditional Chinese medicine act through different mechanisms to upregulate the expression of tumorsuppressing miRNAs and downregulate the expression of oncogenic miRNAs (33). They also inhibit tumor occurrence and development by inducing cell apoptosis to inhibit tumor metastasis, enhancing cell cycle arrest to reduce drug resistance, and by downregulating other pathways (34) (Table 1).

\section{ACTIVE INGREDIENTS OF CHINESE MEDICINE TARGETING MIRNA INDUCE TUMOR APOPTOSIS}

Apoptosis is a basic biological phenomenon, that involves the activation, expression, and regulation of a series of genes. The active ingredients of traditional Chinese medicine regulate target genes by influencing an abnormal expression of miRNAs and inducing tumor cell apoptosis (Figure 1). miR-21 inhibits apoptosis in various tumor cells (71-73). Ginsenoside Rh2 is a natural monosome of ginseng total saponin, and its anti-cancer effects have been demonstrated in various tumors. A former report showed that ginsenoside Rh2 inhibited Bcl-2 by increasing miR-21 levels, which induced apoptosis and significantly decreased leukemia cell viability (35). PTEN is a classical anti-oncogene, the inhibition of PTEN is key for cell apoptosis, mainly relying on the phosphorylation and dephosphorylation of Akt. In FTC-133 human follicular thyroid cells, the alkaloid Chinese medicine active ingredient matrine is induced by upregulating the PTEN/ Akt signaling pathway via the downregulating miR-21 (39) it induces apoptosis of TPC-1 human thyroid cancer cells (40). Similarly, the reverse quantitative polymerase chain reaction of an extract of Magnolia officinalis revealed that magnolol could induce abnormal expression of miRNA in human osteosarcoma cells, with miR-21 showing a very strong ability to downregulate mRNAs. Recent evidence has suggested that Honokiol is able to suppress the $P I 3 K / A K T$ signaling pathway; however, it was reactivated by miR-21 overexpression. Honokiol inhibits proliferation and induces apoptosis by regulating the $m i R-21 /$ 
TABLE 1 | Detailed information on Chinese medicine active ingredients targeting miRNAs.

\begin{tabular}{|c|c|c|c|c|c|}
\hline $\begin{array}{l}\text { Active } \\
\text { Compound }\end{array}$ & Types of cancer & miRNA & Target Genes & Related Hallmark & Reference \\
\hline Ginsenoside Rh2 & Acute myeloid leukemia & $\operatorname{miR}-21$ & $\mathrm{Bcl}-2$ & Induce apoptosis & (35) \\
\hline Ginsenoside Rh2 & Human liver cancer & miR-21 & MCL1/Nrf2/Bcl-2 & Induce apoptosis & (36) \\
\hline Ginsenoside Rh2 & Prostate cancer & $\mathrm{miR}-4295$ & CDKN1A & Anti-proliferation & (37) \\
\hline Ginsenoside Rh2 & Lung adenocarcinoma & miR-491 & MMP-9 & Anti-metastasis & $(38)$ \\
\hline Matrine & Human thyroid cancer & miR-21 & PTEN/p-Akt & Induce apoptosis & $(39,40)$ \\
\hline Honokiol & Osteosarcoma & miR-21 & PTEN/PI3K/AKT & Induce apoptosis & (41) \\
\hline Berberine & Non-small cell lung cancer & miR-19a & TF/MAPK & Induce apoptosis & $(42)$ \\
\hline Baicalin & Colon cancer & miR-217 & DKK1 & Induce apoptosis & (33) \\
\hline Baicalin & Hepatoma & miR-3127-5p & PI3K/Akt & $\begin{array}{l}\text { Cell cycle arrest } \\
\text { Anti-proliferation }\end{array}$ & $(43)$ \\
\hline Resveratrol & Breast cancer & miR-122-5p/miR-542-3p & XIAP/Bcl-2 & Induce apoptosis & (44) \\
\hline Resveratrol & Acute lymphoblastic leukemia & miR-196b/miR-1290 & Caspase-3 & $\begin{array}{l}\text { Induce apoptosis/anti-migration/cycle } \\
\text { arrest }\end{array}$ & $(45)$ \\
\hline Resveratrol & Cancer & miR-326 & PKM2 & Induce apoptosis & $(46)$ \\
\hline Resveratrol & Breast cancer & $\begin{array}{l}\text { miR-34a/miR-424/miR- } \\
503\end{array}$ & Bcl2/p53 & Anti-proliferation & $(47)$ \\
\hline $\begin{array}{l}\text { Triacetyl } \\
\text { resveratrol }\end{array}$ & Pancreatic cancer & miR-200 & Shh & Anti-MET process/Anti-metastasis & $(48)$ \\
\hline Resveratrol & $\begin{array}{l}\text { Low } \\
\text { invasive breast cancer }\end{array}$ & $m i R-122-5 p$ & $\mathrm{Bcl} 2 / \mathrm{CDKs}$ & Enhance chemosensitivity & $(49)$ \\
\hline Resveratrol & Colorectal cancer & miR-200c & Vimentin/ZEB1 & Anti-MET process/anti-metastasis & $(50)$ \\
\hline Ginsenoside Rg3 & Oral squamous cell carcinoma & $\mathrm{miR}-221$ & PI3K/AKT, MAPK/ERK & Anti-EMT process & $(51)$ \\
\hline Ginsenoside Rg3 & Ovarian cancer & $\mathrm{miR}-145$ & DNMT3AFFSCN1 & Anti-EMT process & $(52)$ \\
\hline Camptothecin & Cancer & miR-125b & Bak1/Mcl1/p53 & Induce apoptosis & (53) \\
\hline Camptothecin & Cervical cancer & $\mathrm{miR}-15 \mathrm{a} / 16$ & Rictor & Enhance chemosensitivity & $(54)$ \\
\hline Paeoniflorin & Gastric carcinoma & miR-124 & PI3K/AKt/STAT3 & Anti-proliferation & $(55)$ \\
\hline Paeoniflorin & Human glioma cells & $\mathrm{miR}-16$ & MMP-9 & Anti-proliferation/induce apoptosis & (56) \\
\hline Paeoniflorin & Multiple myeloma & miR-29b & MMP-2 & Anti-proliferation/induce apoptosis & $(57)$ \\
\hline Shikonin & Glioblastoma & $\operatorname{miR}-143$ & BAG3 & Induce apoptosis & (58) \\
\hline Shikonin & $\begin{array}{l}\text { Endometrioid endometrial } \\
\text { cancer }\end{array}$ & miR-106b & $\mathrm{AKT} / \mathrm{mTOR}$ & Anti-proliferation/Induce apoptosis & $(59)$ \\
\hline Shikonin & Gastric carcinoma & $\mathrm{miR}-195$ & PI3K/AKT & Anti-migration/anti-invasion & $(60)$ \\
\hline Shikonin & Cervical Cancer & $m i R-183-5 p$ & E-cadherin & Anti-migration/anti-invasion & (61) \\
\hline Shikonin & Retinoblastoma & miR-34a/miR-202 & MYCN & Anti-proliferation & (62) \\
\hline Celastrol & Ovarian carcinoma & $\operatorname{miR}-21$ & $\mathrm{PI} 3 \mathrm{~K} / \mathrm{p}-\mathrm{Akt} / \mathrm{NF}-\kappa \mathrm{B}$ & Induce apoptosis & (63) \\
\hline Celastrol & Colon cancer & miR-21 & PI3KJAKT/GSK-3 $\beta$ & Anti-proliferation & $(64)$ \\
\hline Celastrol & Gastric cancer & miR-21 & $\begin{array}{l}\text { MMP9/Nimentin } \\
\text { Cyclin D1/CDK6 }\end{array}$ & Anti-migration/induces cell cycle arrest & (65) \\
\hline Celastrol & Gastric cancer & miR-21 & $\mathrm{P} 27 / \mathrm{mTOR}$ & Induces cell cycle arrest & (66) \\
\hline Celastrol & Prostate cancer & miR-101 & NA & Induces autophagy & $(67)$ \\
\hline Celastrol & Prostate cancer & $\mathrm{miR}-17-92 a$ & NA & Induces autophagy & (68) \\
\hline Celastrol & Lung adenocarcinoma & $\mathrm{miR}-24 / \mathrm{miR}-181 \mathrm{~b}$ & STAT3 & Anti-proliferation & (69) \\
\hline Celastrol & Lung adenocarcinoma & $\operatorname{miR}-33 a-5 p$ & $\begin{array}{l}\text { mTOR/p-p70S6K/p- } \\
\text { 4EBP1 }\end{array}$ & Enhance chemosensitivity & (70) \\
\hline
\end{tabular}

PTEN/PI3K/AKT signaling pathway in human osteosarcoma cells (41).

A previous report described that $\mathrm{Rh} 2$ reduces the expression levels of MCL1 and Nrf2, suppresses colony formation, and induces HepG2 cell apoptosis by inhibiting miR-146a-5p in HepG2 cells (36). Berberine is a quaternary ammonium alkaloid isolated from Coptis chinensis. It inhibits the growth of non-smallcell lung cancer via the miR-19a/TF/MAPK axis and promotes apoptosis. A previous study of the mechanism of anti-tumor baicalin in human colon cancer showed that baicalin induced colon cancer cell apoptosis via the Wnt signaling pathway mediated by $m i R-217 / D D K 1$, in which $D D K 1$ was identified as a direct downstream target gene of miR-217 (33). A previous study showed that resveratrol regulated the apoptosis and cell cycle of breast cancer cells by regulating miRNAs such as miR-125b-5p,
miR-200C-3p, miR-409-3p, miR-122-5p, and miR-542-3p. Resveratrol-mediated miRNA modulation regulates key antiapoptotic and cell cycle proteins, including $B c l-2, \mathrm{X}$-linked inhibitor of apoptosis protein, and CDKs, which are critical for its activity. Among these, miR-542-3p and miR-122-5P play key roles in resveratrol-mediated apoptosis of MCF-7 and MDA-MB231 breast cancer cells, respectively (44). Resveratrol significantly reduced miR-196b/miR-1290 expression in the T-ALL (T-cell acute lymphoblastic leukemia) TTL-104 and B-ALL (B-cell acute lymphoblastic leukemia) SUP-B15 cell lines and upregulated the expression of IGFBP3. As a miR-196b/miR-1290 inhibitor, resveratrol was further demonstrated to exert antitumor effects on ALL cells including antiproliferation, cell cycle arrest, apoptosis and inhibition of migration (45). Pyruvate kinase PKM2 is highly expressed in various tumors. The expression of miR-326 was 


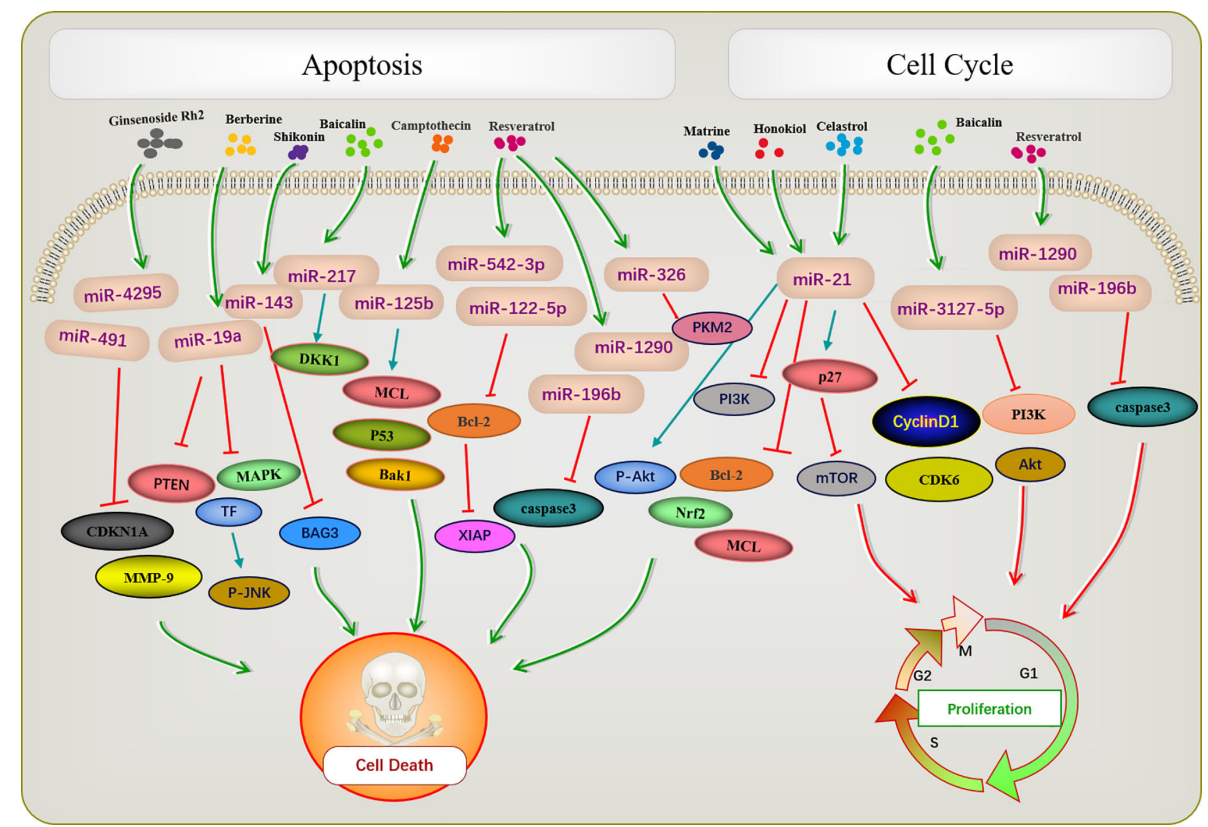

FIGURE 1 | Active ingredients of Chinese medicine targeting miRNAs induce tumor apoptosis and cell cycle blocking.

increased after resveratrol treatment, and $m i R-326 / P K M 2-$ mediated stress and mitochondrial dysfunction were involved in apoptosis induced by resveratrol (46). Camptothecin, a cytotoxic quinoline alkaloid, is an anti-cancer compound found in plants. Deep sequencing analysis of miRNA expression profiles during the camptothecin-induced apoptosis showed that 79 miRNAs were downregulated post-treatment (74). A study of camptothecin verified that miR-125b was down-regulated in camptothecin induced apoptosis in cancer cells. Camptothecin induced apoptosis in cancer cells through miR-125b-mediated mitochondrial pathways by targeting the 3'-untranslated (UTR) regions of Bak1, Mcl1, and p53 (53). In glioblastoma stem cells, miR-143 expression was downregulated after shikonin administration, whereas the regulation factor BAG3 was upregulated. Notably, miR-143 overexpression reversed this phenomenon and enhanced the anti-tumor activity of shikonin in glioblastoma stem cells (58). Celastrol is found in the root of Celastrus orbiculatus, belonging to the family Celastraceae. It can regulate apoptosis-promoting signaling pathways (75). Celastrol suppresses cellular proliferation and induces apoptosis of ovarian cancer OVCAR3 cells by downregulating miR-21 to inhibit the $P I 3 K / P-A k t-N F-\kappa B$ signaling pathway, thereby revealing a potential therapeutic approach (63).

\section{ACTIVE INGREDIENTS OF CHINESE MEDICINE TARGET MIRNAS TO BLOCK TUMOR CELL CYCLE}

The occurrence of most tumors is related to the disruption of cell cycle regulation, leading to uncontrolled cell growth. Many active ingredients of Chinese medicine play an anti-tumor role by blocking the tumor cell cycle and inhibiting cell proliferation (Figure 1). For instance, in patients with acute lymphoblastic leukemia (ALL), a study demonstrated that the expression of IGFBP3 was decreased in ALL patients. The authors further identified that miR-196b and miR-1290 were overexpressed in TALL TALL-104 and B-ALL SUP-B15 cell lines, respectively. As an miR-196b/miR-1290 inhibitor, resveratrol was further demonstrated to exert antitumor effects on ALL cells including cell cycle arrest. Resveratrol blocks T-ALL T-ALL-104 cells during the G1 phase and the B-ALL SUP-B15 cells in the S phase by inhibiting miR-196b/miR-1290 (45). Baicalin upregulates miR-3127-5p, which increases $p 21 / C D K N 1 A$ and $P 27 / C D K N 1 B$ expression to inhibit cell proliferation arresting the cell cycle in $\mathrm{S}$ and G2/M phases in Bel-7402 cells (43). Celastrol caused G2/M cell cycle arrest that was accompanied by the down-regulation of miR-21 expression. Further study showed that celastrol inhibited p27 protein degradation by inhibiting the miR-21 and mTOR signaling pathways in BGC823 and MGC-803 cells. The effect of celastrol on cell cycle arrest of gastric cancer cells was due to an increase in the p27 protein level via inhibition of the miR-21-mTOR signaling pathway (66).

\section{ACTIVE INGREDIENTS OF CHINESE MEDICINE TARGETING MIRNA INHIBIT TUMOR CELL PROLIFERATION}

Many traditional Chinese medicines regulate cell proliferation through miRNAs (Figure 2). Paeoniflorin is a monoterpene glycoside with various anti-cancer activities and is derived 


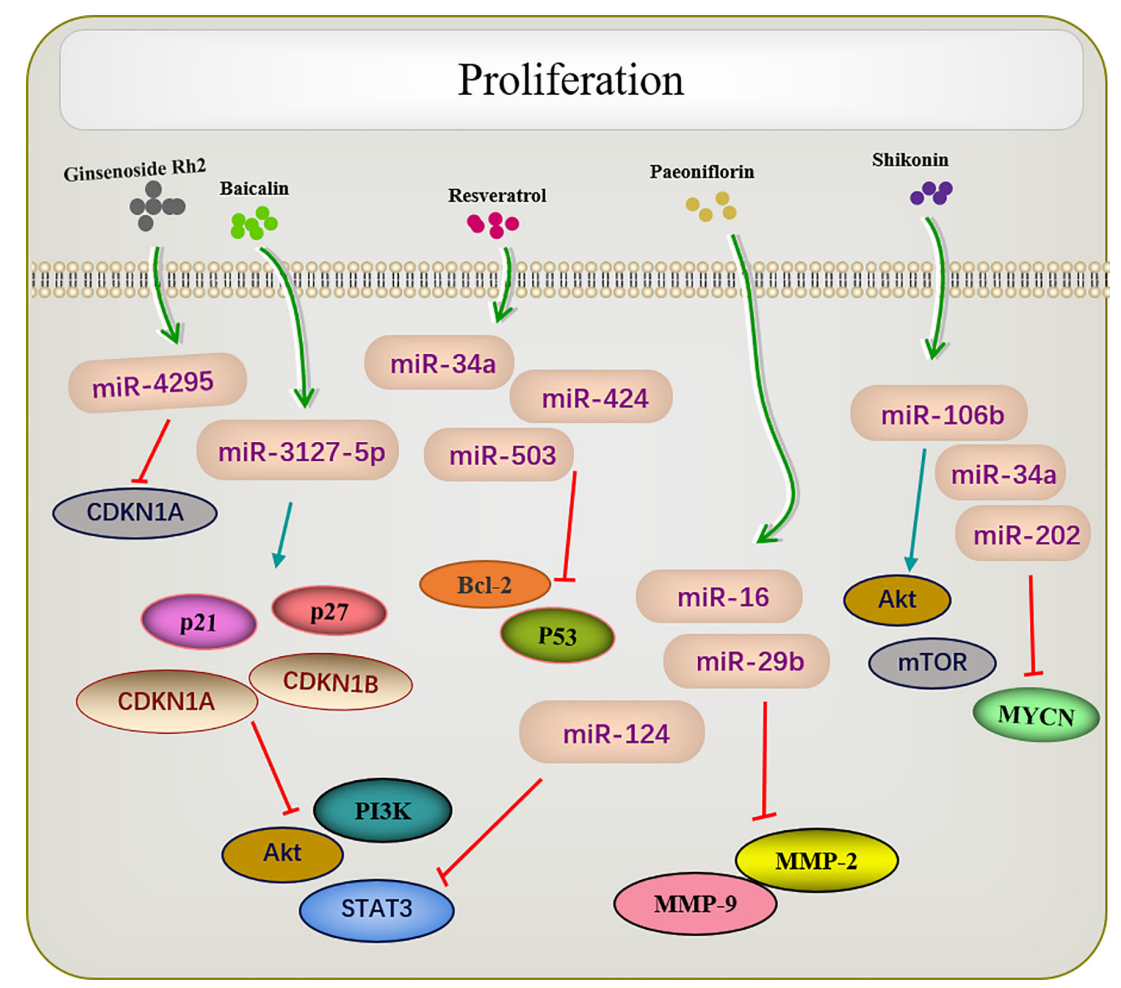

FIGURE 2 | Active ingredients of Chinese medicine targeting miRNAs inhibit tumor cell proliferation.

from Paeonia lactiflora. Studies have shown that paeoniflorin has broad-spectrum anti-tumor activities against various cancers (76), including those of liver (77), lungs (78), breast (79), and pancreas (80). miR-124 levels are significantly increased in paeoniflorin-treated MGC-803 cells, which inhibits PI3K/Akt and $p$-STAT3 expression. A PI3K agonist or STAT3 overexpression can reverse effects of paeoniflorin on MGC-803 cell proliferation (55).

Shikonin, a natural naphthoquinone isolated from traditional Chinese herbs. miR-106b is one of the most significantly downregulated miRNAs among the several miRNAs dysregulated by shikonin. miR-106b targets the tumor suppressor gene phosphatase and tensin homolog (PTEN), thereby modulating $A K T / m T O R$ signaling pathway and ultimately inhibiting the proliferation of endometrial cancer cells (59). An earlier report investigated changes in the proliferation of the retinoblastoma cell lines Y-79 and WeriRB-1 after shikonin administration. The results revealed that shikonin upregulated miR-34a and miR-202 expression and directly targeted the oncogene $M Y C N$ to degrade its mRNA while inhibiting the proliferation of retinoblastoma cells (62).

Several studies have shown that celastrol can inhibit tumor cell proliferation in several types of cancers. For example, in colon cancer cells, the overexpression of miR-21 enhanced cell viability, inhibited apoptosis, increase Bcl-2 expression, and decreased Bax levels; these effects were reversed by celastrol. As enzymes are involved in cell survival, the PI3K/AKT/GSK-3 $\beta$ pathway provides important signals for tumor cell proliferation Clastrol may inhibit colon cancer cell proliferation by negatively regulating the PI3K/AKT/GSK-3 pathways via miR-21 (64). Similar results were reported in lung adenocarcinoma, in which celastrol inhibited cell proliferation and induced apoptosis by regulating the expression levels of miR-24 and miR-181b (69).

Another study showed that ginsenoside Rh2 inhibited the proliferation of prostate cancer cells in a dose-dependent manner, and no CDKN1A cell cycle inhibitor was observed in the increased protein of ginsenoside $\mathrm{Rh} 2$. Screening all candidate miRNAs for binding to the $3^{\prime}$-untranslated region of CDKN1A showed that miR-4295 was dose-dependently inhibited by ginsenoside Rh2. Therefore, comprehensive experimental investigations revealed that ginsenoside $\mathrm{Rh} 2$ inhibits prostate cancer cell growth by inhibiting miRNA-4295, which activates CDKN1A (37).

\section{ACTIVE INGREDIENTS OF CHINESE MEDICINE TARGETING MIRNA INHIBIT TUMOR CELL METASTASIS AND INVASION}

The metastasis and invasion are essential feature characterizing the biological behavior of malignant tumors. The active 
ingredients of traditional Chinese medicine can inhibit the invasion and metastasis of tumors by regulating miRNA (Figure 3). EMT is an important prerequisite for tumor cell metastasis. The miR-200 family inhibits EMT, thereby inhibiting tumor metastasis. A previous study reported that triacetyl resveratrol, a derivative of resveratrol, inhibited pancreatic cancer growth and EMT by upregulating the expression of the members of the miR-200 family and targeting the Shh pathway (48). Moreover, resveratrol increased the expression of miR-200c to inhibit cell proliferation and invasion in HCT116 cells (50). Ginseng saponin Rg3 suppressed EMT in oral squamous cell carcinoma and ovarian cancer via miR-221 (51) and miR-145 (52). E-cadherin, the most common EMT protein, plays an important role in tumor invasion, and the loss of E-cadherin expression promotes tumor and EMT. In the cervical cancer cell lines HeLa and C33a, Shikonin inhibits EMT by inducing miR183-5p expression via E-cadherin (61). Similarly, miR-17-5p expression was upregulated in triple-negative breast cancer. The PTEN is a direct target of miR-17-5p. Studies have shown that increased expression of PTEN can inhibit miR-17-5p and reduce the expression of $A k t$ and $P$ - $A k t$, thereby inhibiting EMT and the migration and invasion of triple-negative breast cancer cells (81).

Shikonin can inhibit tumor migration and invasion via modulating miRNA-mediated regulation of multiple pathways. miR-195 is an important member of the micro-15/16/195/424/ 497 family and can be used as a diagnostic biomarker in breast cancer (82). In NCI-N87 cells, shikonin inhibited the proliferation, migration, and invasion by regulating miR-195 to inhibit the $P I 3 K / A K T$ signaling pathway (60). Matrix metalloproteinases (MMPs) play important roles in mediating angiogenesis, metastasis, and invasion. $M M P-2 / 9$ expression is related to the progression of many tumors, such as colon cancer (83), neuroblastoma (84), and bladder cancer (85). Paeoniflorin regulated miR-16/29b, which targeted MMP-9/2 (56) to inhibit the growth and invasion of multiple myeloma cells (57). Celastrol can downregulate miR-21 and MMP9 and regulate the expression of the cell migration protein vimentin; this reduces the migration and invasion ability of MKN45 gastric cancer cells (65). Resveratrol significantly inhibited cell migration in T-cell ALL T-ALL-104 and B-cell ALL SUP-B15 cells by inhibiting miR-196b/miR-1290 (45).

\section{ACTIVE INGREDIENTS OF CHINESE MEDICINE TARGETING MIRNA REVERSE TUMOR CELL RESISTANCE}

Increasing evidence has revealed that dysfunctional miRNAs significantly affect chemotherapy resistance. Active ingredients of Chinese medicine play an important role in reducing the toxic and side effects of chemotherapy and improving resistance to chemotherapy (Figure 3). A previous study showed that lowinvasive breast cancer cells were resistant to amycin and this resistance was reversed by resveratrol, which also targeted the regulatory inhibitor miR-122-5p to influence the cell cycle and apoptosis (49). Increased autophagy during chemotherapy can promote tumor apoptosis or mediate autophagy-related apoptosis. miR-15a and miR-16 effectively induce autophagy,

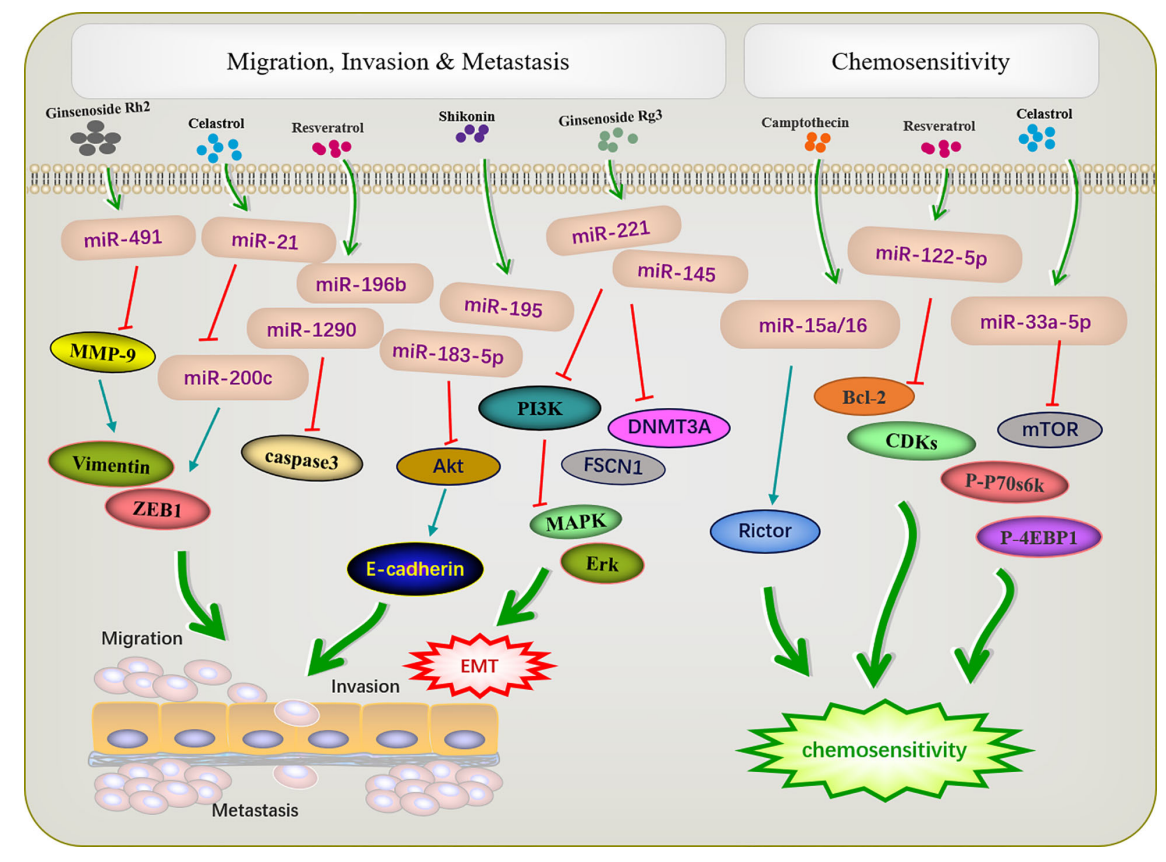

FIGURE 3 | Active ingredients of Chinese medicine targeting miRNAs inhibit tumor cell metastasis and invasion, and reverse tumor cell resistance. 
enhancing the therapeutic effect of camptothecin (54). Celastrol reduced $m T O R, P-P 70 S 6 K$, and $p-4 E B P 1$ expression by increased miR33a-5p to inhibited tumor growth (70).

\section{THE ACTIVE INGREDIENTS OF TRADITIONAL CHINESE MEDICINE REGULATE THE ANTI-TUMOR MECHANISM OF LNCRNAS}

Generally, lncRNAs are defined as molecules comprising more than 200 nucleotides lacking protein-coding capacity. However, more recently, lncRNAs have been reported to regulate gene expression (86). Meanwhile, various active ingredients in Chinese medicines, such as curcumin and resveratrol, modulate tumor development via lncRNA expression regulation in vitro and in vivo (Table 2). In gemcitabine-resistant pancreatic ductal adenocarcinoma cell, a phenolic compound extracted from turmeric, curcumin, desensitizes chemotherapy-resistant pancreatic ductal adenocarcinoma via inhibiting the PRC2-PVT1$c-M y c$ axis. Hence, emerging evidence suggested that curcumin may be an effective sensitizing agent for chemotherapeutic drugs (96). Moreover, curcumin induces the expression of the lncRNA PINT to inhibit acute lymphoblastic leukemia cell growth (88).

Resveratrol is a non-flavonoid polyphenol compound with a wide pharmacological spectrum of anti-cancer, anti-inflammatory, anti-microbial, and antioxidant activity (97). One study on lung cancer reported the upregulation of $21 \operatorname{lncRNAs}$ and downregulation of 19 lncRNAs resveratrol treated A549 cells. Among these, decreased levels of the lncRNA AK001796 weakened the inhibitory effect of resveratrol on cell proliferation (91). Resveratrol inhibits cell proliferation, migration, and invasion by downregulating AK001796 and NEAT1 in lung cancer and multiple myeloma $(91,92)$. Similarly, triptolide and isoflavone calycosin inhibit tumor cell growth by inhibiting specific lncRNAs in nasopharyngeal cancer. Triptonide inhibits human nasopharyngeal carcinoma cell growth via disrupting lncRNA THOR-IGF2BP1 signaling. Conversely, ectopic lncRNA THOR overexpression inhibits Triptonide-induced cytotoxicity in NPC cells (95).
One of the representative lncRNAs, H19, is recognized as a cancer biomarker and is associated with the occurrence of esophageal cancer (98), colorectal cancer (99), liver cancer (100), breast cancer (101), bladder cancer (102), and stomach cancer. Furthermore, reduced expression of H19 can inhibit cancer development $(103,104)$. Specifically, curcumin inhibited cell proliferation via $c-M y c / H 19$ pathway, which reduced the expression of H19 in stomach cancer cells. This indicated that curcumin is a potential drug for gastric cancer (87). Moreover, microarray data identified $H 19$ as a potential target of Huaier (a fungal parasite on locust trees), the extract from which reduced the expression of $H 19$, while also reducing the viability of breast cancer cells by inducing apoptosis via regulation of the H19-miR675-5p-CBL axis (105). Besides, certain lncRNAs and miRNAs mutually restrict and regulate target genes to achieve tumor inhibition. For example, in bladder cancer, H19 can directly bind miR-29b-3p to derepress the target DNMT3B. Further, upregulating H19 antagonizes miR-29b-3p-mediated proliferation, migration, and epithelial-mesenchymal transition (EMT) suppression in bladder cells. This evidence demonstrated, for the first time, that $\mathrm{H} 19$ may function as a competing endogenous RNA (ceRNA) for miR-29b-3p and relieve the suppression of DNMT3B, leading to EMT and metastasis of bladder cancer (106). In 2011, a new theory was proposed that ceRNAs and miRNA response elements could mediate the interactions between mRNA pseudogenes and some ncRNAs to form a large-scale regulatory network in the transcriptome and serve as a "new language" for "mutual conversation" (107) (Figure 4). These networks are characterized by sponge activity, in which ncRNA interacts with the target gene to competitively bind or inhibit. In addition, ceRNAs have been identified as key regulatory factors in cancer $(108,109)$. PVT1, located downstream of the proto-oncogene $M y c$ in chromosome 8q24, was used as a ceRNA of miR-216b and miR-152 in non-smallcell lung cancer and osteosarcoma to promote the tumor resistance to anti-cancer drugs $(110,111)$. In prostate cancer cells, IncRNA-ROR and the stem cell marker Oct4 mRNA contain binding regions for miR-145 and directly compete with this microRNA. Curcumin reduced the expression of endogenous $\ln c R N A-R O R$ and effectively increased the available concentration of miR-145 in human prostate cancer stem cells,

TABLE 2 | Detailed information on Chinese medicine active ingredients targeting IncRNAs.

\begin{tabular}{|c|c|c|c|c|}
\hline Active Compound & LncRNA & Cancer & Related Hallmark & Reference \\
\hline Curcumin & $\mathrm{H} 19$ & Gastric cancer & Proliferation & $(87)$ \\
\hline Curcumin & GAS5 & Breast cancer & Apoptosis & $(12)$ \\
\hline Curcumin & PINT & Acute lymphoblastic leukemia & Proliferation & (88) \\
\hline Curcumin & ROR & Prostate cancer & Proliferation & (31) \\
\hline Curcumin & PANDAR & Colorectal cancer & Apoptosis & (89) \\
\hline Curcumin & MEG3 & Ovarian cancer & Drug resistance & (90) \\
\hline Resveratrol & AK001796 & Lung cancer & Proliferation/cycle arrest & (91) \\
\hline Resveratrol & NEAT1 & Multiple myeloma & Proliferation/migration & (92) \\
\hline Matrine & LINC00472 & Bladder carcinoma & Growth/metastasis & (93) \\
\hline Artesunate & UCA1 & Prostate cancer & Apoptosis/migration & (94) \\
\hline Triptolide & THOR & Nasopharyngeal carcinoma & Growth & (95) \\
\hline Calycosin & EWSAT1 & Nasopharyngeal carcinoma & Growth & (30) \\
\hline
\end{tabular}




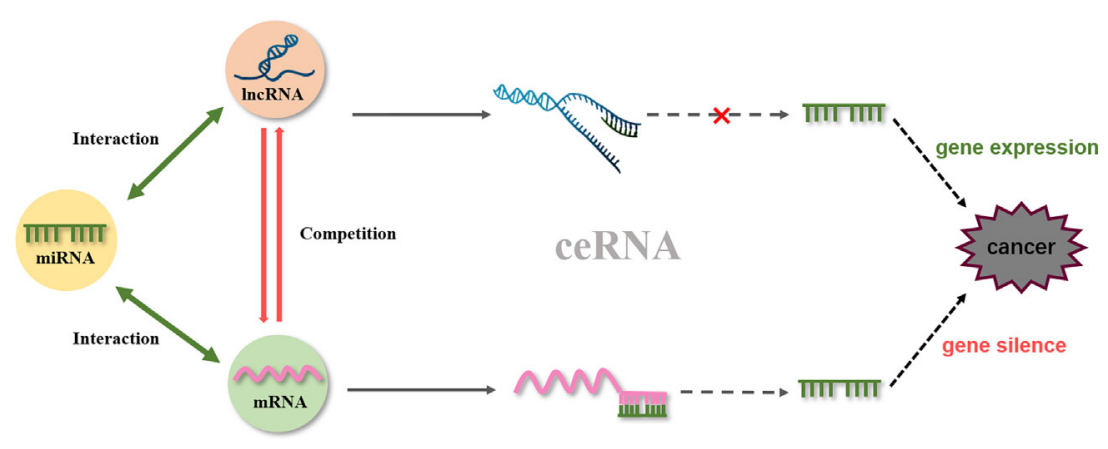

FIGURE 4 | ceRNA network.

where miR-145 prevented cell proliferation by decreasing Oct4 expression (31). The ceRNA hypothesis has revealed new mechanisms of RNA interactions, which incentivized the analysis of ncRNA role in cancer development.

\section{REGULATION OF THE ANTI-TUMOR MECHANISM BY CIRCRNA AND OTHER NCRNAS}

As potential targets for the active ingredients of Chinese medicine, circRNA, siRNA, rRNA, and other non-coding RNAs are involved in tumor development. Some circRNAs affect cancer biogenesis in diverse manners, such as by functioning as miRNA sponges, combining with RNA-binding proteins, acting as transcription factors, and affecting protein translation (112). Matrine decreased circRNA-104075 and Bcl-9 expression significantly via inhibition of PI3K/AKT and Wnt- $\beta$ catenin pathways,it suppressed cell viability while induceing apoptosis and autophagy in glioma cell line U251 (113). Another study shows that matrine down-regulated the levels of circ_0027345 and HOXD3, and up-regulated miR-345-5p expression. Meanwhile, matrine restrained tumor growth, invasion and promoted autophagy of HCC by regulating the circ_0027345/miR-345-5p/HOXD3 axis in vivo (114). Curcumin has antioxidant and anti-cancer properties, and it has also been used as a radiosensitizer. A study compared the differences in circRNA levels in NPC cell lines after radiotherapy and after treatment with curcumin, using a high-throughput microarray. Finally, it was demonstrated by reverse transcriptionquantitative polymerase chain reaction assay and wound healing assay that curcumin could enhance radiosensitization of NPC cell lines via mediating regulation of tumor stem-like cells by the "hsa_circRNA_102115"- "hsa-miR-335-3p""MAPK1" interaction network (115). At present, although circRNA has shown significant activity in the treatment of cancer, there are few reports on the regulation of circRNA by Active Ingredients of Chinese Medicine, which is also an important direction for future researchers to concern and research. circRNA has been expected to become a new molecular biomarker for the clinical diagnosis, treatment and prognosis, and the potential target for targeted therapy. siRNAs are double-stranded RNAs of 20-25 nucleotides and are involved in RNA interference; they regulate gene expression in a specific manner. Multiple synthetic siRNAs can achieve long-term silencing of target genes without interfering with endogenous microRNA pathways. Ginsenoside Rh2 downregulated PSTAT3/STAT3 and intracellular oxidative stress by upregulating PPAR. In response to siRNA-mediated knockdown of PPAR, STAT3 and intracellular oxidative stress were increased (116). rRNA is the most abundant type of RNA in cells. In lung cancer cells, triptolide interrupts rRNA synthesis by inhibiting transcriptional activation of RNA Pol $I$ and UBF, thereby activating the apoptosis regulators caspase 9 and caspase 3 to inhibit BCL2 and induce apoptosis and cell cycle arrest (117).

\section{DISCUSSION}

During cancer development, abnormal ncRNAs modulate cell proliferation, migration, and invasion by regulating the expression of proto-oncogenes and tumor suppressor genes. Many active ingredients of traditional Chinese medicine, such as resveratrol, matrine, and berberine, have been evaluated in vivo and in vitro to target specific ncRNA and shown to play anticancer roles. This review summarized the finding regarding 16 active ingredients of traditional Chinese medicine that can target miRNAs, lncRNAs, and other ncRNAs, thereby playing an effective role in suppressing cancer growth. Among the ncRNAs regulated by Chinese medicine active ingredients, miR-21 is the most reported ncRNA and is extensively studied in various cancers. It is involved in most of the cancer-related processes, such as cell apoptosis, proliferation, migration, and cell cycle. These findings indicate that miR21 is one of the promising ncRNAs to develop targeted therapeutic agents for many types of cancer. Some active ingredients of traditional Chinese medicine, such as Ginsenoside Rh2 and Resveratrol, promote apoptosis by regulating ncRNAs to target common apoptosis-related target genes, such as BCL2 and Caspase3. 
In conclusion, traditional Chinese medicine's active ingredients significantly ameliorate malignant neoplasms via ncRNA regulation, suggesting that active ingredients of traditional Chinese medicine may become alternative therapeutic agents for cancer in the future. At present, most studies have reported that the active ingredients of traditional Chinese medicine mainly target one kind of ncRNA for cancer treatment. However, ceRNA mechanism suggests that several kinds of ncRNA have complex interactions in cancer treatment. Therefore, we need to further explore the detailed anti-cancer mechanism and clinical safety of each of the active ingredients of traditional Chinese medicine. We hope that this review on the regulation of ncRNA by active ingredients of traditional Chinese medicine on tumor will be helpful for future research studies on anti-cancer of traditional Chinese medicine and provide a reference for their clinical application.

\section{REFERENCES}

1. Sohyla R, Shahram S, Alireza Z, Arash Z, Fariba S. Cancer CMJJoG. a comparative study of spatial distribution of gastrointestinal cancers in poverty and affluent strata (kermanshah metropolis, iran). J Gastrointest Cancer (2018) 50(4):838-47. doi: 10.1007/s12029-018-0163-7

2. Hong M, Wang N, Tan HY, Tsao SW, Feng Y. MicroRNAs and chinese medicinal herbs: new possibilities in cancer therapy. Cancers (2015) 7 (3):1643-57. doi: 10.3390/cancers7030855

3. Romano G, Veneziano D, Acunzo M, Croce CM. Small non-coding RNA and cancer. Carcinogenesis (2017) 38(5):485-91. doi: 10.1093/carcin/bgx026

4. Long J, Xiong J, Bai Y, Mao J, Lin J, Xu W, et al. Construction and investigation of a lncrna-associated cerna regulatory network in cholangiocarcinoma. Front Oncol (2019) 9:649. doi: 10.3389/fonc.2019. 00649

5. Lin C, Yang L. Long noncoding RNA in cancer: wiring signaling circuitry. Trends Cell Biol (2018) 28(4):287-301. doi: 10.1016/j.tcb.2017.11.008

6. Hao NB, He YF, Li XQ, Wang K, Wang RL. The role of miRNA and lncRNA in gastric cancer. Oncotarget (2017) 8(46):81572-82. doi: 10.18632/ oncotarget.19197

7. Zhao J, Du P, Cui P, Qin Y, Hu C, Wu J, et al. LncRNA PVT1 promotes angiogenesis via activating the STAT3/VEGFA axis in gastric cancer. Oncogene (2018) 37(30):4094-109. doi: 10.1038/s41388-018-0250-z

8. Wei GH, Wang X. lncRNA MEG3 inhibit proliferation and metastasis of gastric cancer via p53 signaling pathway. Eur Rev Med Pharmacol Sci (2017) 21(17):3850-6.

9. Nie W, Ge HJ, Yang XQ, Sun X, Huang H, Tao X, et al. LncRNA-UCA1 exerts oncogenic functions in non-small cell lung cancer by targeting miR193a-3p. Cancer Lett (2016) 371(1):99-106. doi: 10.1016/j.canlet. 2015.11.024

10. Fang Z, Chen W, Yuan Z, Liu X, Jiang H. LncRNA-MALAT1 contributes to the cisplatin-resistance of lung cancer by upregulating MRP1 and MDR1 via STAT3 activation. Biomed Pharmacother (2018) 101:536-42. doi: 10.1016/ j.biopha.2018.02.130

11. Chen F, Chen J, Yang L, Liu J, Zhang X, Zhang Y, et al. Extracellular vesiclepackaged HIF-1 $\alpha$-stabilizing lncRNA from tumour-associated macrophages regulates aerobic glycolysis of breast cancer cells. Nat Cell Biol (2019) 21 (4):498-510. doi: 10.1038/s41556-019-0299-0

12. Gu J, Wang Y, Wang X, Zhou D, Shao C, Zhou M, et al. Downregulation of IncRNA GAS5 confers tamoxifen resistance by activating miR-222 in breast cancer. Cancer Lett (2018) 434:1-10. doi: 10.1016/j.canlet.2018.06.039

13. Zhang Y, Pitchiaya S, Cieślik M, Niknafs YS, Tien JC, Hosono Y, et al. Analysis of the androgen receptor-regulated lncRNA landscape identifies a role for ARLNC1 in prostate cancer progression. Nat Genet (2018) 50 (6):814-24. doi: 10.1038/s41588-018-0120-1

\section{AUTHOR CONTRIBUTIONS}

TL and SH participated in writing, editing, and making figures. ZQ and DL read and approved the final manuscript. All authors contributed to the article and approved the submitted version.

\section{FUNDING}

This work was supported by the National Natural Science Foundation of China (grant 81973712,81803680,82003985), China Postdoctoral Science Foundation (grant 2020M670825, 2020T130568), Jilin Province Science and Technology Development Project in China (grant 20170309005YY, 20200504005YY), Jilin Province TCM science and technology project (grant 2020041).

14. Mitobe Y, Takayama KI, Horie-Inoue K, Inoue S. Prostate cancer-associated IncRNAs. Cancer Lett (2018) 418:159-66. doi: 10.1016/j.canlet.2018.01.012

15. Li H, Yu B, Li J, Su L, Yan M, Zhu Z, et al. Overexpression of lncRNA H19 enhances carcinogenesis and metastasis of gastric cancer. Oncotarget (2014) 5(8):2318-29. doi: 10.18632/oncotarget.1913

16. Hammond SM. An overview of microRNAs. Adv Drug Deliver Rev (2015) 87:3-14. doi: 10.1016/j.addr.2015.05.001

17. Ashrafizadeh M, Ahmadi Z, Mohammadinejad R, Farkhondeh T, Samarghandian S. MicroRNAs mediate the anti-tumor and protective effects of ginsenosides. Nutr Cancer (2020) 72(8):1264-75. doi: 10.1080/ 01635581.2019.1675722

18. Solomon MC, Radhakrishnan RA. MicroRNA's - The vibrant performers in the oral cancer scenario. Japanese Dental Sci Rev (2020) 56(1):85-9. doi: 10.1016/j.jdsr.2020.04.001

19. Yan S, Wang H, Chen X, Liang C, Shang W, Wang L, et al. MiR-182-5p inhibits colon cancer tumorigenesis, angiogenesis, and lymphangiogenesis by directly downregulating VEGF-C. Cancer Lett (2020) 488:18-26. doi: $10.1016 /$ j.canlet.2020.04.021

20. Zhang X, Zhang L, Chen M, Liu D. miR-324-5p inhibits gallbladder carcinoma cell metastatic behaviours by downregulation of transforming growth factor beta 2 expression. Artif cells Nanomed Biotechnol (2020) 48 (1):315-24. doi: 10.1080/21691401.2019.1703724

21. Xia H, Zhao Y. miR-155 is high-expressed in polycystic ovarian syndrome and promotes cell proliferation and migration through targeting PDCD4 in KGN cells. Artif cells Nanomed Biotechnol (2020) 48(1):197-205. doi: 10.1080/21691401.2019.1699826

22. Mackenzie NC, Staines KA, Zhu D, Genever P, Macrae VE. miRNA-221 and miRNA-222 synergistically function to promote vascular calcification. Cell Biochem Funct (2014) 32(2):209-16. doi: 10.1002/cbf.3005

23. Li M, Zhang D, Cheng J, Liang J, Yu F. Ginsenoside Rh2 inhibits proliferation but promotes apoptosis and autophagy by down-regulating microRNA-638 in human retinoblastoma cells. Exp Mol Pathol (2019) 108:17-23. doi: 10.1016/j.yexmp.2019.03.004

24. Chen Y, Shang H, Zhang S, Zhang X. Ginsenoside Rh2 inhibits proliferation and migration of medulloblastoma Daoy by down-regulation of microRNA31. J Cell Biochem (2018) 119(8):6527-34. doi: 10.1002/jcb.26716

25. Li N, Wang C, Zhang P, You S. Emodin inhibits pancreatic cancer EMT and invasion by up-regulating microRNA-1271. Mol Med Rep (2018) 18 (3):3366-74. doi: 10.3892/mmr.2018.9304

26. Zheng F, Li J, Ma C, Tang X, Tang Q, Wu J, et al. Novel regulation of miR$34 a-5 p$ and HOTAIR by the combination of berberine and gefitinib leading to inhibition of EMT in human lung cancer. J Cell Mol Med (2020) 24 (10):5578-92. doi: 10.1111/jcmm.15214

27. Ripani P, Delp J, Bode K, Delgado ME, Dietrich L, Betzler VM, et al. Thiazolides promote G1 cell cycle arrest in colorectal cancer cells by 
targeting the mitochondrial respiratory chain. Oncogene (2020) 39 (11):2345-57. doi: 10.1038/s41388-019-1142-6

28. Xiang Y, Guo Z, Zhu P, Chen J, Huang YJCM. Traditional Chinese medicine as a cancer treatment: modern perspectives of ancient but advanced science. Cancer Med (2019) 8(5):1958-75. doi: 10.1002/cam4.2108

29. Yan Z, Lai Z, Lin J. Anticancer properties of traditional chinese medicine. Combinatorial Chem High throughput screening (2017) 20(5):423-9. doi: 10.2174/1386207320666170116141818

30. Kong L, Li X, Wang H, He G, Tang A. Calycosin inhibits nasopharyngeal carcinoma cells by influencing EWSAT1 expression to regulate the TRAF6related pathways. Biomed Pharmacother (2018) 106:342-8. doi: 10.1016/ j.biopha.2018.06.143

31. Liu T, Chi H, Chen J, Chen C, Huang Y, Xi H, et al. Curcumin suppresses proliferation and in vitro invasion of human prostate cancer stem cells by ceRNA effect of miR-145 and lncRNA-ROR. Gene (2017) 631:29-38. doi: 10.1016/j.gene.2017.08.008

32. Tang J, Ahmad A, Sarkar FH. MicroRNAs in breast cancer therapy. Curr Pharm design (2014) 20(33):5268-74. doi: 10.2174/138161282066614 0128205239

33. Jia Y, Chen L, Guo S, Li Y. Baicalin induced colon cancer cells apoptosis through miR-217/DKK1-mediated inhibition of Wnt signaling pathway. Mol Biol Rep (2019) 46(2):1693-700. doi: 10.1007/s11033-019-04618-9

34. Farooqi AA, Khalid S, Ahmad A. Regulation of cell signaling pathways and miRNAs by resveratrol in different cancers. Int J Mol Sci (2018) 19(3):652. doi: $10.3390 / \mathrm{ijms} 19030652$

35. Wang X, Wang Y. Ginsenoside Rh2 mitigates pediatric leukemia through suppression of Bcl-2 in leukemia cells. Cell Physiol Biochem Int J Exp Cell Physiol Biochem Pharmacol (2015) 37(2):641-50. doi: $10.1159 / 000430383$

36. Chen W, Chu S, Li H, Qiu Y. MicroRNA-146a-5p enhances ginsenoside $\mathrm{Rh} 2$-induced anti-proliferation and the apoptosis of the human liver cancer cell line HepG2. Oncol Lett (2018) 16(4):5367-74. doi: 10.3892/ol.2018.9235

37. Gao Q, Zheng J. Ginsenoside Rh2 inhibits prostate cancer cell growth through suppression of microRNA-4295 that activates CDKN1A. Cell Proliferation (2018) 51(3):e12438. doi: 10.1111/cpr.12438

38. Chen Y, Zhang Y, Song W, Zhang Y, Dong X, Tan M. Ginsenoside Rh2 Inhibits migration of lung cancer cells under hypoxia via mir-491. Anticancer Agents Medicinal Chem (2019) 19(13):1633-41. doi: 10.2174/ 1871520619666190704165205

39. Li Q, Zhang S, Wang M, Dong S, Wang Y, Liu S, et al. Downregulated miR21 mediates matrine-induced apoptosis via the PTEN/Akt signaling pathway in FTC-133 human follicular thyroid cancer cells. Oncol Lett (2019) 18 (4):3553-60. doi: 10.3892/ol.2019.10693

40. Zhao L, Zhang X, Cui S. Matrine inhibits TPC-1 human thyroid cancer cells via the miR-21/PTEN/Akt pathway. Oncol Lett (2018) 16(3):2965-70. doi: 10.3892/ol.2018.9006

41. Yang J, Zou Y, Jiang D. Honokiol suppresses proliferation and induces apoptosis via regulation of the miR-21/PTEN/PI3K/AKT signaling pathway in human osteosarcoma cells. Int J Mol Med (2018) 41(4):1845-54. doi: $10.3892 /$ ijmm. 2018.3433

42. Chen QQ, Shi JM, Ding Z, Xia Q, Zheng TS, Ren YB, et al. Berberine induces apoptosis in non-small-cell lung cancer cells by upregulating miR-19a targeting tissue factor. Cancer Manage Res (2019) 11:9005-15. doi: $10.2147 / \mathrm{cmar} . S 207677$

43. Bie B, Sun J, Li J, Guo Y, Jiang W, Huang C, et al. Baicalein, a Natural AntiCancer Compound, Alters MicroRNA Expression Profiles in Bel-7402 Human Hepatocellular Carcinoma Cells. Cell Physiol Biochem Int J Exp Cell Physiol Biochem Pharmacol (2017) 41(4):1519-31. doi: 10.1159/ 000470815

44. Venkatadri R, Muni T, Iyer AK, Yakisich JS, Azad N. Role of apoptosisrelated miRNAs in resveratrol-induced breast cancer cell death. Cell Death Dis (2016) 7(2):e2104. doi: 10.1038/cddis.2016.6

45. Zhou W, Wang S, Ying Y, Zhou R, Mao P. miR-196b/miR-1290 participate in the antitumor effect of resveratrol via regulation of IGFBP3 expression in acute lymphoblastic leukemia. Oncol Rep (2017) 37(2):1075-83. doi: 10.3892/or.2016.5321

46. Wu H, Wang Y, Wu C, Yang P, Li H, Li Z. Resveratrol induces cancer cell apoptosis through MiR-326/PKM2-Mediated ER stress and mitochondrial fission. J Agric Food Chem (2016) 64(49):9356-67. doi: 10.1021/ acs.jafc.6b04549

47. Otsuka K, Yamamoto Y, Ochiya T. Regulatory role of resveratrol, a microRNA-controlling compound, in HNRNPAl expression, which is associated with poor prognosis in breast cancer. Oncotarget (2018) 9 (37):24718-30. doi: 10.18632/oncotarget.25339

48. Fu J, Shrivastava A, Shrivastava SK, Srivastava RK, Shankar S. Triacetyl resveratrol upregulates miRNA-200 and suppresses the Shh pathway in pancreatic cancer: A potential therapeutic agent. Int J Oncol (2019) 54 (4):1306-16. doi: 10.3892/ijo.2019.4700

49. Zhang W, Jiang H, Chen Y, Ren F. Resveratrol chemosensitizes adriamycinresistant breast cancer cells by modulating miR-122-5p. J Cell Biochem (2019) 120(9):16283-92. doi: 10.1002/jcb.28910

50. Karimi Dermani F, Saidijam M, Amini R, Mahdavinezhad A, Heydari K, Najafi R. Resveratrol inhibits proliferation, invasion, and epithelialmesenchymal transition by increasing miR-200c expression in HCT-116 colorectal cancer cells. J Cell Biochem (2017) 118(6):1547-55. doi: 10.1002/ jcb. 25816

51. Cheng Z, Xing D. Ginsenoside Rg3 inhibits growth and epithelialmesenchymal transition of human oral squamous carcinoma cells by down-regulating miR-221. Eur J Pharmacol (2019) 853:353-63. doi: 10.1016/j.ejphar.2019.03.040

52. Li J, Lu J, Ye Z, Han X, Zheng X, Hou H, et al. 20(S)-Rg3 blocked epithelialmesenchymal transition through DNMT3A/miR-145/FSCN1 in ovarian cancer. Oncotarget (2017) 8(32):53375-86. doi: 10.18632/oncotarget.18482

53. Zeng CW, Zhang XJ, Lin KY, Ye H, Feng SY, Zhang H, et al. Camptothecin induces apoptosis in cancer cells via microRNA-125b-mediated mitochondrial pathways. Mol Pharmacol (2012) 81(4):578-86. doi: 10.1124/mol.111.076794

54. Huang N, Wu J, Qiu W, Lyu Q, He J, Xie W, et al. MiR-15a and miR-16 induce autophagy and enhance chemosensitivity of Camptothecin. Cancer Biol Ther (2015) 16(6):941-8. doi: 10.1080/15384047.2015.1040963

55. Zheng YB, Xiao GC, Tong SL, Ding Y, Wang QS, Li SB, et al. Paeoniflorin inhibits human gastric carcinoma cell proliferation through up-regulation of microRNA-124 and suppression of PI3K/Akt and STAT3 signaling. World J Gastroenterol (2015) 21(23):7197-207. doi: 10.3748/wjg.v21.i23.7197

56. Li W, Qi Z, Wei Z, Liu S, Wang P, Chen Y, et al. Paeoniflorin inhibits proliferation and induces apoptosis of human glioma cells via microRNA-16 upregulation and matrix metalloproteinase-9 downregulation. Mol Med Rep (2015) 12(2):2735-40. doi: 10.3892/mmr.2015.3718

57. Wang S, Liu W. Paeoniflorin inhibits proliferation and promotes apoptosis of multiple myeloma cells via its effects on microRNA-29b and matrix metalloproteinase-2. Mol Med Rep (2016) 14(3):2143-9. doi: 10.3892/ mmr.2016.5498

58. Liu J, Qu CB, Xue YX, Li Z, Wang P, Liu YH. MiR-143 enhances the antitumor activity of shikonin by targeting BAG3 expression in human glioblastoma stem cells. Biochem Biophys Res Commun (2015) 468(1-2):10512. doi: 10.1016/j.bbrc.2015.10.153

59. Huang C, Hu G. Shikonin suppresses proliferation and induces apoptosis in endometrioid endometrial cancer cells via modulating miR-106b/PTEN/ AKT/mTOR signaling pathway. Biosci Rep (2018) 38(2):BSR20171546. doi: 10.1042/bsr20171546

60. Jia L, Zhu Z, Li H, Li Y. Shikonin inhibits proliferation, migration, invasion and promotes apoptosis in NCI-N87 cells via inhibition of PI3K/AKT signal pathway. Artif cells Nanomed Biotechnol (2019) 47(1):2662-9. doi: 10.1080/ 21691401.2019.1632870

61. Tang Q, Liu L, Zhang H, Xiao J, Hann SS. Regulations of miR-183-5p and snail-mediated shikonin-reduced epithelial-mesenchymal transition in cervical cancer cells. Drug design Dev Ther (2020) 14:577-89. doi: 10.2147/ dddt.S236216

62. Su Y, Lu S, Li J, Deng L. Shikonin-mediated up-regulation of miR-34a and miR-202 inhibits retinoblastoma proliferation. Toxicol Res (2018) 7(5):90712. doi: $10.1039 / \mathrm{c} 8 \mathrm{tx} \times 00079 \mathrm{~d}$

63. Zhang H, Li J, Li G, Wang S. Effects of celastrol on enhancing apoptosis of ovarian cancer cells via the downregulation of microRNA-21 and the suppression of the PI3K/Akt-NF- $\mathrm{KB}$ signaling pathway in an in vitro model of ovarian carcinoma. Mol Med Rep (2016) 14(6):5363-8. doi: 10.3892/mmr.2016.5894 
64. Ni H, Han Y, Jin X. Celastrol inhibits colon cancer cell proliferation by downregulating miR-21 and PI3K/AKT/GSK-3 $\beta$ pathway. Int J Clin Exp Pathol (2019) 12(3):808-16.

65. Yao SS, Han L, Tian ZB, Yu YN, Zhang Q, Li XY, et al. Celastrol inhibits growth and metastasis of human gastric cancer cell MKN45 by downregulating microRNA-21. Phytother Res PTR (2019) 33(6):1706-16. doi: $10.1002 /$ ptr.6359

66. Sha M, Ye J, Luan ZY, Guo T, Wang B, Huang JX. Celastrol induces cell cycle arrest by MicroRNA-21-mTOR-mediated inhibition p27 protein degradation in gastric cancer. Cancer Cell Int (2015) 15:101. doi: 10.1186/ s12935-015-0256-3

67. Guo J, Huang X, Wang H, Yang H. Celastrol induces autophagy by targeting AR/miR-101 in prostate cancer cells. PLoS One (2015) 10(10):e0140745. doi: 10.1371/journal.pone.0140745

68. Guo J, Mei Y, Li K, Huang X, Yang H. Downregulation of miR-17-92a cluster promotes autophagy induction in response to celastrol treatment in prostate cancer cells. Biochem Biophys Res Commun (2016) 478(2):804-10. doi: 10.1016/j.bbrc.2016.08.029

69. Yan YF, Zhang HH, Lv Q, Liu YM, Li YJ, Li BS, et al. Celastrol suppresses the proliferation of lung adenocarcinoma cells by regulating microRNA-24 and microRNA-181b. Oncol Lett (2018) 15(2):2515-21. doi: 10.3892/ ol.2017.7593

70. Li YJ, Sun YX, Hao RM, Wu P, Zhang LJ, Ma X, et al. miR-33a-5p enhances the sensitivity of lung adenocarcinoma cells to celastrol by regulating mTOR signaling. Int J Oncol (2018) 52(4):1328-38. doi: 10.3892/ijo.2018.4276

71. Canfrán-Duque A, Rotllan N, Zhang X, Fernández-Fuertes M, RamírezHidalgo C, Araldi E, et al. Macrophage deficiency of miR-21 promotes apoptosis, plaque necrosis, and vascular inflammation during atherogenesis. EMBO Mol Med (2017) 9(9):1244-62. doi: 10.15252/emmm.201607492

72. Xiao J, Pan Y, Li XH, Yang XY, Feng YL, Tan HH, et al. Cardiac progenitor cell-derived exosomes prevent cardiomyocytes apoptosis through exosomal miR-21 by targeting PDCD4. Cell Death Dis (2016) 7(6):e2277. doi: 10.1038/ cddis. 2016.181

73. Cheng X, Zhang G, Zhang L, Hu Y, Zhang K, Sun X, et al. Mesenchymal stem cells deliver exogenous miR-21 via exosomes to inhibit nucleus pulposus cell apoptosis and reduce intervertebral disc degeneration. J Cell Mol Med (2018) 22(1):261-76. doi: 10.1111/jcmm.13316

74. Erdoğan İ, Coşacak M, Nalbant A, Akgül B. Deep sequencing reveals two Jurkat subpopulations with distinct miRNA profiles during camptothecininduced apoptosis. Turkish J Biol = Turk biyoloji dergisi (2018) 42(2):113-22. doi: 10.3906/biy-1710-62

75. Kashyap D, Sharma A, Tuli HS, Sak K, Mukherjee T, Bishayee A. Molecular targets of celastrol in cancer: recent trends and advancements. Crit Rev Oncol/Hematol (2018) 128:70-81. doi: 10.1016/j.critrevonc.2018.05.019

76. Xiang Y, Zhang Q, Wei S, Huang C, Li Z, Gao Y. Paeoniflorin: a monoterpene glycoside from plants of Paeoniaceae family with diverse anticancer activities. J Pharm Pharmacol (2020) 72(4):483-95. doi: 10.1111/jphp.13204

77. Liu H, Zang L, Zhao J, Wang Z, Li L. Paeoniflorin inhibits cell viability and invasion of liver cancer cells via inhibition of Skp2. Oncol Lett (2020) 19 (4):3165-72. doi: 10.3892/ol.2020.11424

78. Wu Q, Chen GL, Li YJ, Chen Y, Lin FZ. Paeoniflorin inhibits macrophagemediated lung cancer metastasis. Chin J Natural Medicines (2015) 13 (12):925-32. doi: 10.1016/s1875-5364(15)30098-4

79. Zhang J, Yu K, Han X, Zhen L, Liu M, Zhang X, et al. Paeoniflorin influences breast cancer cell proliferation and invasion via inhibition of the Notch-1 signaling pathway. Mol Med Rep (2018) 17(1):1321-5. doi: 10.3892/ mmr.2017.8002

80. Li Y, Gong L, Qi R, Sun Q, Xia X, He H, et al. Paeoniflorin suppresses pancreatic cancer cell growth by upregulating HTRA3 expression. Drug Design Dev Ther (2017) 11:2481-91. doi: 10.2147/dddt.S134518

81. Li J, Lai Y, Ma J, Liu Y, Bi J, Zhang L, et al. miR-17-5p suppresses cell proliferation and invasion by targeting ETV1 in triple-negative breast cancer. BMC Cancer (2017) 17(1):745. doi: 10.1186/s12885-017-3674-x

82. Liu Y, Tang D, Zheng S, Su R, Tang Y. Serum microRNA-195 as a potential diagnostic biomarker for breast cancer: a systematic review and metaanalysis. Int J Clin Exp Pathol (2019) 12(11):3982-91.
83. Hsu HH, Kuo WW, Day CH, Shibu MA, Li SY, Chang SH, et al. Taiwanin E inhibits cell migration in human LoVo colon cancer cells by suppressing MMP-2/9 expression via p38 MAPK pathway. Environ Toxicol (2017) 32 (8):2021-31. doi: 10.1002/tox.22379

84. Li XY, Huang GH, Liu QK, Yang XT, Wang K, Luo WZ, et al. Porf-2 Inhibits Tumor Cell Migration Through the MMP-2/9 Signaling Pathway in Neuroblastoma and Glioma. Front Oncol (2020) 10:975. doi: 10.3389/ fonc. 2020.00975

85. Chen Z, Zhang F, Zhang S, Ma L. The down-regulation of SNCG inhibits the proliferation and invasiveness of human bladder cancer cell line 5637 and suppresses the expression of MMP-2/9. Int J Clin Exp Pathol (2020) 13 (7):1873-9.

86. Peng WX, Koirala P, Mo YY. LncRNA-mediated regulation of cell signaling in cancer. Oncogene (2017) 36(41):5661-7. doi: 10.1038/onc.2017.184

87. Liu G, Xiang T, Wu QF, Wang WX. Curcumin suppresses the proliferation of gastric cancer cells by downregulating H19. Oncol Lett (2016) 12(6):515662. doi: 10.3892/ol.2016.5354

88. Garitano-Trojaola A, José-Enériz ES, Ezponda T, Unfried JP, Carrasco-León A, Razquin N, et al. Deregulation of linc-PINT in acute lymphoblastic leukemia is implicated in abnormal proliferation of leukemic cells. Oncotarget (2018) 9(16):12842-52. doi: 10.18632/oncotarget.24401

89. Chen T, Yang P, Wang H, He ZY. Silence of long noncoding RNA PANDAR switches low-dose curcumin-induced senescence to apoptosis in colorectal cancer cells. OncoTargets Ther (2017) 10:483-91. doi: 10.2147/ott.S127547

90. Zhang J, Liu J, Xu X, Li L. Curcumin suppresses cisplatin resistance development partly via modulating extracellular vesicle-mediated transfer of MEG3 and miR-214 in ovarian cancer. Cancer Chemother Pharmacol (2017) 79(3):479-87. doi: 10.1007/s00280-017-3238-4

91. Yang Q, Xu E, Dai J, Liu B, Han Z, Wu J, et al. A novel long noncoding RNA AK001796 acts as an oncogene and is involved in cell growth inhibition by resveratrol in lung cancer. Toxicol Appl Pharmacol (2015) 285(2):79-88. doi: 10.1016/j.taap.2015.04.003

92. Geng W, Guo X, Zhang L, Ma Y, Wang L, Liu Z, et al. Resveratrol inhibits proliferation, migration and invasion of multiple myeloma cells via NEAT1mediated Wnt/ $\beta$-catenin signaling pathway. Biomed Pharmacother $=$ Biomedecine Pharmacotherapie (2018) 107:484-94. doi: 10.1016/ j.biopha.2018.08.003

93. Li L, Qi F, Wang K. Matrine restrains cell growth and metastasis by upregulating LINC00472 in bladder carcinoma. Cancer Manage Res (2020) 12:1241-51. doi: $10.2147 / \mathrm{cmar} . S 224701$

94. Zhou Y, Wang X, Zhang J, He A, Wang YL, Han K, et al. Artesunate suppresses the viability and mobility of prostate cancer cells through UCA1, the sponge of miR-184. Oncotarget (2017) 8(11):18260-70. doi: 10.18632/ oncotarget. 15353

95. Wang SS, Lv Y, Xu XC, Zuo Y, Song Y, Wu GP, et al. Triptonide inhibits human nasopharyngeal carcinoma cell growth via disrupting Lnc-RNA THOR-IGF2BP1 signaling. Cancer Lett (2019) 443:13-24. doi: 10.1016/ j.canlet.2018.11.028

96. Yoshida K, Toden S, Ravindranathan P, Han H, Goel A. Curcumin sensitizes pancreatic cancer cells to gemcitabine by attenuating PRC2 subunit EZH2, and the lncRNA PVT1 expression. Carcinogenesis (2017) 38(10):1036-46. doi: 10.1093/carcin/bgx065

97. Amiri A, Tehran MM, Asemi Z, Shafiee A, Hajighadimi S, Moradizarmehri $\mathrm{S}$, et al. Role of resveratrol in modulating microRNAs in human diseases: from cancer to inflammatory disorder. Curr Medicinal Chem (2019) 2 (28):360-76. doi: 10.2174/0929867326666191212102407

98. Zhou YW, Zhang H, Duan CJ, Gao Y, Cheng YD, He D, et al. miR-675-5p enhances tumorigenesis and metastasis of esophageal squamous cell carcinoma by targeting REPS2. Oncotarget (2016) 7(21):30730-47. doi: 10.18632 /oncotarget. 8950

99. Li S, Hua Y, Jin J, Wang H, Du M, Zhu L, et al. Association of genetic variants in lncRNA H19 with risk of colorectal cancer in a Chinese population. Oncotarget (2016) 7(18):25470-7. doi: 10.18632/oncotarget. 8330

100. Li X, Liu R. Long non-coding RNA H19 in the liver-gut axis: a diagnostic marker and therapeutic target for liver diseases. Exp Mol Pathol (2020) 115:104472. doi: 10.1016/j.yexmp.2020.104472 
101. Collette J, Le Bourhis X, Adriaenssens E. Regulation of human breast cancer by the long non-coding RNA H19. Int J Mol Sci (2017) 18(11):2319. doi: 10.3390/ijms18112319

102. Taheri M, Omrani MD, Ghafouri-Fard S. Long non-coding RNA expression in bladder cancer. Biophys Rev (2018) 10(4):1205-13. doi: 10.1007/s12551017-0379-y

103. Zhang L, Zhou Y, Huang T, Cheng AS, Yu J, Kang W, et al. The interplay of LncRNA-H19 and its binding partners in physiological process and gastric carcinogenesis. Int J Mol Sci (2017) 18(2):450. doi: 10.3390/ijms18020450

104. Ghafouri-Fard S, Esmaeili M, Taheri M. H19 lncRNA: Roles in tumorigenesis. Biomed Pharmacother (2020) 123:109774. doi: 10.1016/ j.biopha.2019.109774

105. Wang J, Wang X, Chen T, Jiang L, Yang Q. Huaier extract inhibits breast cancer progression through a LncRNA-H19/MiR-675-5p pathway. Cell Physiol Biochem Int J Exp Cell Physiol Biochem Pharmacol (2017) 44 (2):581-93. doi: 10.1159/000485093

106. Lv M, Zhong Z, Huang M, Tian Q, Jiang R, Chen J. IncRNA H19 regulates epithelial-mesenchymal transition and metastasis of bladder cancer by miR29b-3p as competing endogenous RNA. Biochim Biophys Acta Mol Cell Res (2017) 1864(10):1887-99. doi: 10.1016/j.bbamcr.2017.08.001

107. Salmena L, Poliseno L, Tay Y, Kats L. Pandolfi PP. A ceRNA hypothesis: the Rosetta Stone of a hidden RNA language? Cell (2011) 146(3):353-8. doi: 10.1016/j.cell.2011.07.014

108. Ogunwobi OO, Kumar A. Chemoresistance mediated by ceRNA networks associated with the PVT1 locus. Front Oncol (2019) 9:834. doi: 10.3389/ fonc.2019.00834

109. Anastasiadou E, Jacob LS, Slack FJ. Non-coding RNA networks in cancer. Nat Rev Cancer (2018) 18(1):5-18. doi: 10.1038/nrc.2017.99

110. Chen L, Han X, Hu Z, Chen L. The PVT1/miR-216b/Beclin-1 regulates cisplatin sensitivity of NSCLC cells via modulating autophagy and apoptosis. Cancer Chemother Pharmacol (2019) 83(5):921-31. doi: 10.1007/s00280019-03808-3

111. Sun ZY, Jian YK, Zhu HY, Li B. lncRNAPVT1 targets miR-152 to enhance chemoresistance of osteosarcoma to gemcitabine through activating c-MET/
PI3K/AKT pathway. Pathology Res Pract (2019) 215(3):555-63. doi: 10.1016/ j.prp.2018.12.013

112. Shang Q, Yang Z, Jia R, Ge S. The novel roles of circRNAs in human cancer. Mol Cancer (2019) 18(1):6. doi: 10.1186/s12943-018-0934-6

113. Chi G, Xu D, Zhang B, Yang F. Matrine induces apoptosis and autophagy of glioma cell line U251 by regulation of circRNA-104075/BCL-9. Chemico Biological Interact (2019) 308:198-205. doi: 10.1016/ j.cbi.2019.05.030

114. Lin S, Zhuang J, Zhu L, Jiang Z. Matrine inhibits cell growth, migration, invasion and promotes autophagy in hepatocellular carcinoma by regulation of circ_0027345/miR-345-5p/HOXD3 axis. Cancer Cell Int (2020) 20:246. doi: 10.1186/s12935-020-01293-w

115. Zhu D, Shao M, Yang J, Fang M, Liu S, Lou D, et al. Curcumin enhances radiosensitization of nasopharyngeal carcinoma via mediating regulation of tumor stem-like cells by a CircRNA network. J Cancer (2020) 11(8):2360-70. doi: $10.7150 /$ jca.39511

116. Tong-Lin Wu T, Tong YC, Chen IH, Niu HS, Li Y, Cheng JT. Induction of apoptosis in prostate cancer by ginsenoside Rh2. Oncotarget (2018) 9 (13):11109-18. doi: 10.18632/oncotarget.24326

117. Wang J, Zhang ZQ, Li FQ, Chen JN, Gong X, Cao BB, et al. Triptolide interrupts rRNA synthesis and induces the RPL23-MDM2-p53 pathway to repress lung cancer cells. Oncol Rep (2020) 43(6):1863-74. doi: 10.3892/ or.2020.7569

Conflict of Interest: The authors declare that the research was conducted in the absence of any commercial or financial relationships that could be construed as a potential conflict of interest.

Copyright $\odot 2021 \mathrm{Liu}, \mathrm{Hu}$, Qiu and Liu. This is an open-access article distributed under the terms of the Creative Commons Attribution License (CC BY). The use, distribution or reproduction in other forums is permitted, provided the original author $(s)$ and the copyright owner $(s)$ are credited and that the original publication in this journal is cited, in accordance with accepted academic practice. No use, distribution or reproduction is permitted which does not comply with these terms. 